\title{
INDOOR THERMAL COMFORT ASSESSMENT OF NATURALLY VENTILATED ATRIUMS IN SINGAPORE
}

\author{
Wong Nyuk Hien ${ }^{1}$, Osrithalita Gabriela ${ }^{2 *}$, Erna Tan $^{3}$, Steve Kardinal Jusuf $^{4}$ \\ ${ }^{1,2,3}$ Department of Building, School of Design and Environment, National University of Singapore, \\ 4 Architecture Drive, Singapore 117566 \\ ${ }^{4}$ Engineering Cluster Sustainable Infrastructural Engineering, Singapore Institute of Technology, \\ 10 Dover Drive, Singapore 138683 \\ *Corresponding author; Email: bdgog@nus.edu.sg/osrithalita.gabriela@gmail.com
}

\begin{abstract}
This research looks into the aspect of Thermal Comfort (TC) in naturally ventilated (NV) buildings, in this case NV atriums. Compared to fully air-conditioned buildings, NV buildings tend to have better indoor air quality (IAQ), but worse TC. Therefore, this research investigates the range of acceptable temperature and wind speed in order to achieve thermal comfort for naturally ventilated atriums. Data was collected through field survey in three different buildings of NV atriums and were used to develop and validate the TC model. The data collected from field survey represent visitors' TC perception in atrium environment, and in-situ environmental measurement also records the characteristics of $\mathrm{NV}$ atrium in each area, such as solar radiation, air temperature, relative humidity, and intermittent wind. At the same time with the indoor field survey, a weather station was installed on the roof of the building to measure the micro-meteorological condition. Thermal comfort prediction model was developed from the statistical analysis of the field survey data. The acceptable range to achieve thermal comfort for $\mathrm{NV}$ atrium was analyzed. The air temperature of $31^{\circ} \mathrm{C}$ was determined as the boundary condition. Based on the result of Predicted Mean Vote (PMV) formula, PMV 1 is the highest acceptable value with wind speed required is $0.51 \mathrm{~m} / \mathrm{s}$ and PMV 0.8 is recommended to achieve the best thermal comfort with wind speed required is $0.78 \mathrm{~m} / \mathrm{s}$.
\end{abstract}

Keywords: Atrium; naturally ventilated; thermal comfort; thermal sensation.

\section{INTRODUCTION}

Throughout the years of assessment and evaluation process of Green Mark (GM) scheme standard from 2005 set by Building and Construction Authority (BCA), it is found that the criteria used for Residential Buildings (RB) have been adopted for Non-Residential Buildings (NRB), and the passing criteria of area weighted wind velocity of $\geq 0.6 \mathrm{~m} / \mathrm{s}$ (BCA, 2013) for developments with higher GM rating is deemed to be not sufficient to assess the natural ventilation (NV) design for NRB.

There is a paradigm shift from heat balancebased thermal comfort models toward adaptive comfort modeling over the last 20 years (de Dear et al, 2014). All adaptive models show implicitly that occupants of NV buildings achieve thermal comfort across a wider range of indoor temperatures than occupants of air-conditioned buildings. In NV buildings, human comfort is more prevalent and needs more attention compared with air-conditioned buildings. The dominant characteristics of tropical buildings are openness to provide efficient ventilation, and shading to provide protection from the sun, rain and insects. Due to the tropical climate condition, buildings are found to be uncomfortably hot and humid at certain times, and higher velocity of wind flow over the human body is required to increase the efficiency of sweat evaporation (Yeang, 1987).

Atrium is a common feature in commercial buildings, mainly as a social function space such as events or gathering. There are several references that talked about the history of atrium/atria. In modern architecture, atrium is an expansive open space that is often several floors high and is covered by a glass roof, big windows, or both (Moosavi et al, 2014).

This research looks into the aspect of Thermal Comfort (TC) in NV buildings, in this case NV atriums. It investigates the range of acceptable temperature and wind speed in order to achieve thermal comfort for naturally ventilated atriums.

This study will help BCA to further ensure sustained building performance, which key strategy would be to minimize energy consumption through the optimization of design.

The research aims to establish alternative evaluation methods and criteria to demonstrate good natural ventilation in NRB buildings. The objectives of this study are as follows:

1. To develop thermal comfort model, analysis and validation; and

2. To recommend the optimum requirement and assessment method to achieve thermal comfort in $\mathrm{NV}$ atriums. 


\section{METHODOLOGY}

\section{Objective and Subjective Measurement}

Data was collected through field survey and used to develop and to validate the TC model. Field survey allows "first-hand" data that help to capture occupants' TC perception in their actual daily environment. The in-situ environmental measurement also records the characteristics of NV buildings, which are dynamic and unpredictable. These NV characteristics such as intermittent wind, solar radiation and high humidity cannot be simulated easily by mechanical means in a chamber thus field survey is considered as the best method for the data collection.

The measurement protocol for the field survey followed Class II protocol of thermal comfort field research (Brager \& De Dear, 1998). There are two groups of data required, i.e. objective and subjective measurement data. Since the human perception is not as simple as "stimulus-response" (cause-effect) phenomenon, the field survey attempted to observe and collect data to comprehend better the complex human perception, behaviour and background. Different physical parameters affect physiological reactions to the environment. All parameters such as air temperature, radiant temperature, surface temperature, air velocity and humidity are the basis for defining criteria for an acceptable thermal environment (Kalz \& Pfafferott, 2014).

The objective measurement measured the air temperature, wind speed, relative humidity and globe temperature near each occupant (respondent), and noted the activity and the clothing level of the respondent while the respondent did the subjective assessment. The objective measurement was conducted at around $0.8-1 \mathrm{~m}$ high from the floor. The measurement was conducted using handheld equipment of Testo 445 as shown in Fig. 1(left). During the indoor field survey, a weather station was installed on the roof of the building to measure the micrometeorological condition. Fig. 1(right) shows the $\mathrm{HOBO}$ weather station. The monitored environmental parameters included ambient temperature, wind speed and wind direction, relative humidity, and solar radiation.

The subjective assessment was formulated into questionnaire form. Some standard questionnaires (response scales) for TC studies are widely used such as ASHRAE and Bedford scales (Chrenko \& Bedford, 1974; McIntyre, 1980). Seven scale of ASHRAE thermal sensation vote and seven scale of Bedford thermal comfort vote are used. By using both scales, the consistency of response between thermal sensation (hot to cold) and perception (uncomfortable-comfortable warm or cold) can be further verified.

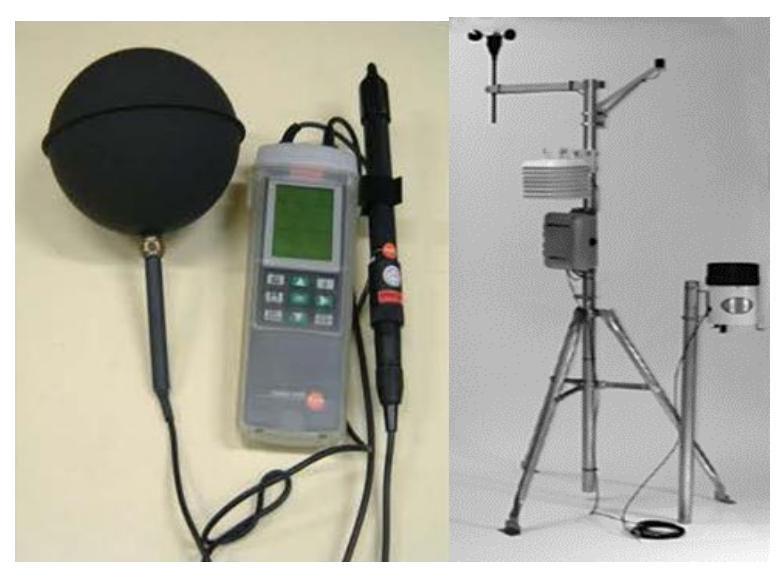

Fig. 1. Handheld Equipment Testo 445 and Weather Station HOBO (Source: author and gayeontech.co).

\section{Thermal Comfort Survey}

For each building, the survey was conducted in different sessions daily, based on the activity of the building i.e. in between 10am to $12 \mathrm{pm}$ (morning session) and in between 1.30pm to $4 \mathrm{pm}$ (afternoon session), and $5 \mathrm{pm}$ to $7.30 \mathrm{pm}$ (evening session) if there is any activity in the evening. The study tried to cover different session in order to capture the thermal perception of different parts of the day. The data collected from the field survey was compared between external and internal environment. Observations were made on the measured data such as clothing level and metabolic rate as well as the sensation and perception data.

The surveys were conducted on the visitors in the atrium area of three different buildings with $\mathrm{NV}$ atriums in Singapore (see Fig. 2).

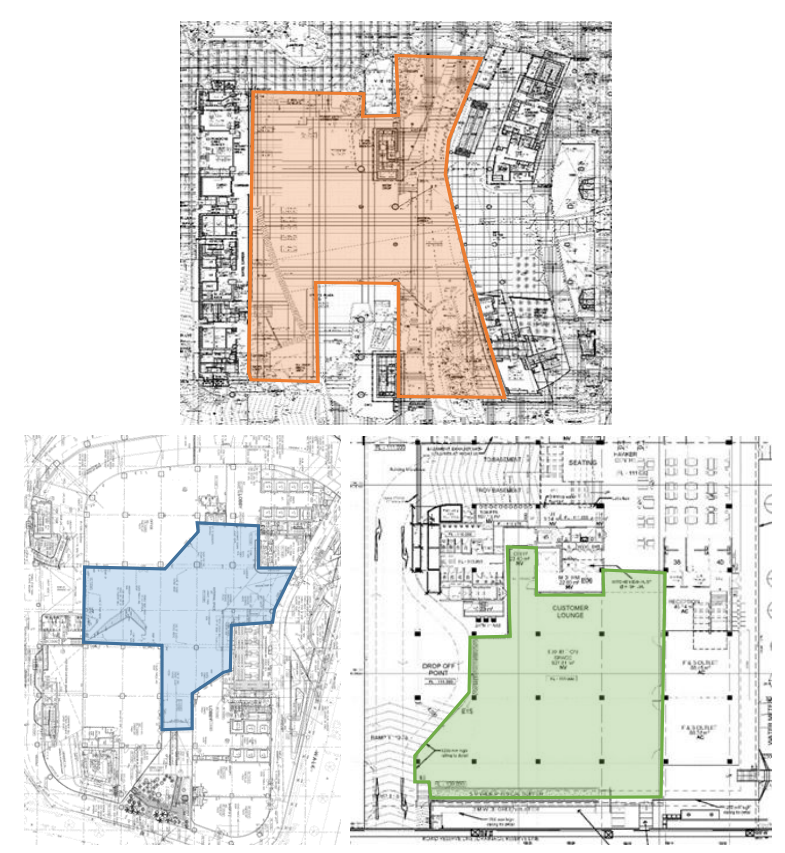

Fig. 2. Naturally Ventilated Atriums (A, B, and C). 
The TC surveys at building A were conducted on $14,15,18$, and 20 January 2016 . Each survey was conducted for 3 sessions: morning session (10am $12 \mathrm{pm})$, afternoon session ( $2 \mathrm{pm}-4 \mathrm{pm})$, and evening session $(6 \mathrm{pm}-8 \mathrm{pm})$. A HOBO weather station was installed on the roof top with no obstruction. Total number of respondent from the survey was 234 .

The TC survey at building B was conducted on 5 April 2016 when the weather condition was bright all day. The survey was conducted continuously from $10 \mathrm{am}$ until $3.30 \mathrm{pm}$, which covered morning and afternoon sessions. There was no evening session because it is an office building where most of the activities end after 5pm. A total number of 120 respondents participated in the TC survey.

The TC surveys at building $C$ were conducted on 18 and 19 July 2016 when the weather condition was bright - partly cloudy. The surveys were conducted for 2 sessions: morning session (10am - 12pm) and afternoon session (1.30pm - 3.30pm). A HOBO weather station was installed on the roof top with no obstruction. A total of 110 respondents agreed to participate in the survey at building $\mathrm{C}$.

Figure 3 (left) shows the typical TC survey in NV atriums and Figure 3 (right) shows the typical installation of weather station on the roof top with no obstruction.

\section{RESULT AND DISCUSSION}

\section{Field Measurement Data}

In total, a total of 464 respondents participated the thermal comfort surveys. Table 1 shows the data sampling distribution on all buildings.

The first two-day survey in building A was on a bright day in the morning and then the weather changed drastically into a cloudy condition in the afternoon and subsequently it was raining in the evening with solar radiation less than $200 \mathrm{~W} / \mathrm{m}^{2}$ and air temperature less than $29^{\circ} \mathrm{C}$. The survey in building $\mathrm{B}$ was during the hottest weather condition among all sites with solar radiation reaching $920 \mathrm{~W} / \mathrm{m}^{2}$ and air temperature ranged $29.7-33.1^{\circ} \mathrm{C}$. The surveys in building $\mathrm{C}$ were during bright to partly cloudy weather condition with solar radiation reaching 800 $\mathrm{W} / \mathrm{m}^{2}$ and air temperature ranged $27.4-32.6^{\circ} \mathrm{C}$. Error! Reference source not found. shows the measured outdoor weather condition during the time of the TC survey.
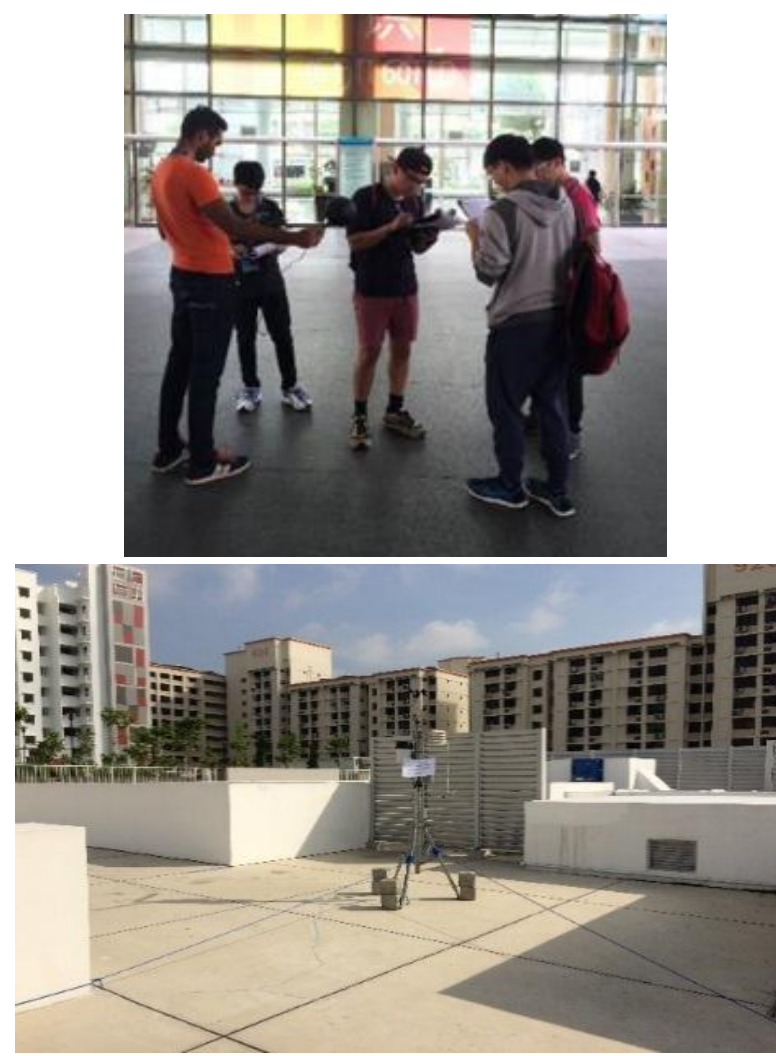

Fig. 3. The Typical Indoor Field Survey (left) and the Typical Installation of Weather Station (right)

Table 1. Data Sampling Distribution on all Sites

\begin{tabular}{|c|c|c|c|c|c|c|c|c|c|c|}
\hline \multirow[b]{2}{*}{ Weather } & \multicolumn{6}{|c|}{ Building A } & \multicolumn{2}{|l|}{ Building B } & \multicolumn{2}{|l|}{ Building C } \\
\hline & Bright & $\begin{array}{l}\text { Partly } \\
\text { Cloudy }\end{array}$ & $\begin{array}{l}\text { Partly } \\
\text { Cloudy }\end{array}$ & Bright & $\begin{array}{l}\text { Partly } \\
\text { Cloudy }\end{array}$ & $\begin{array}{l}\text { Partly } \\
\text { Cloudy }\end{array}$ & Bright & Bright & $\begin{array}{l}\text { Partly } \\
\text { Cloudy }\end{array}$ & Bright \\
\hline Date of survey & \multicolumn{2}{|c|}{ 14-Jan-16 } & \multicolumn{2}{|c|}{ 15-Jan-16 } & $\begin{array}{c}\text { 18-Jan- } \\
16\end{array}$ & 20-Jan-16 & 5-Apr-16 & \multicolumn{2}{|c|}{ 18-Jul-16 } & $\begin{array}{c}\text { 19-Jul- } \\
16\end{array}$ \\
\hline Time of survey & $\begin{array}{l}10 \mathrm{AM}- \\
12 \mathrm{PM}\end{array}$ & $\begin{array}{c}\text { 2PM - } \\
3.30 \mathrm{PM}\end{array}$ & $\begin{array}{l}10 \mathrm{AM}- \\
12 \mathrm{PM}\end{array}$ & $\begin{array}{l}\text { 2PM- } \\
3.30 \mathrm{PM}\end{array}$ & $\begin{array}{l}5 \mathrm{PM}- \\
6 \mathrm{PM}\end{array}$ & $\begin{array}{l}5.30 \mathrm{PM}- \\
7.30 \mathrm{PM}\end{array}$ & $10 \mathrm{AM}-3.30 \mathrm{PM}$ & $\begin{array}{l}10 \mathrm{AM}- \\
12 \mathrm{PM}\end{array}$ & $\begin{array}{l}1.30 \mathrm{PM}- \\
3.30 \mathrm{PM}\end{array}$ & $\begin{array}{c}10 \mathrm{AM}- \\
12 \mathrm{PM}\end{array}$ \\
\hline Number of respondent & \multicolumn{2}{|c|}{95} & \multicolumn{2}{|c|}{72} & 15 & 52 & 120 & \multicolumn{2}{|c|}{88} & 22 \\
\hline $\begin{array}{l}\text { Total of respondents } \\
\text { each building }\end{array}$ & \multicolumn{6}{|c|}{234} & 120 & \multicolumn{3}{|c|}{110} \\
\hline Total respondents & & & & & & 464 & & & & \\
\hline
\end{tabular}


Outdoor Weather Condition

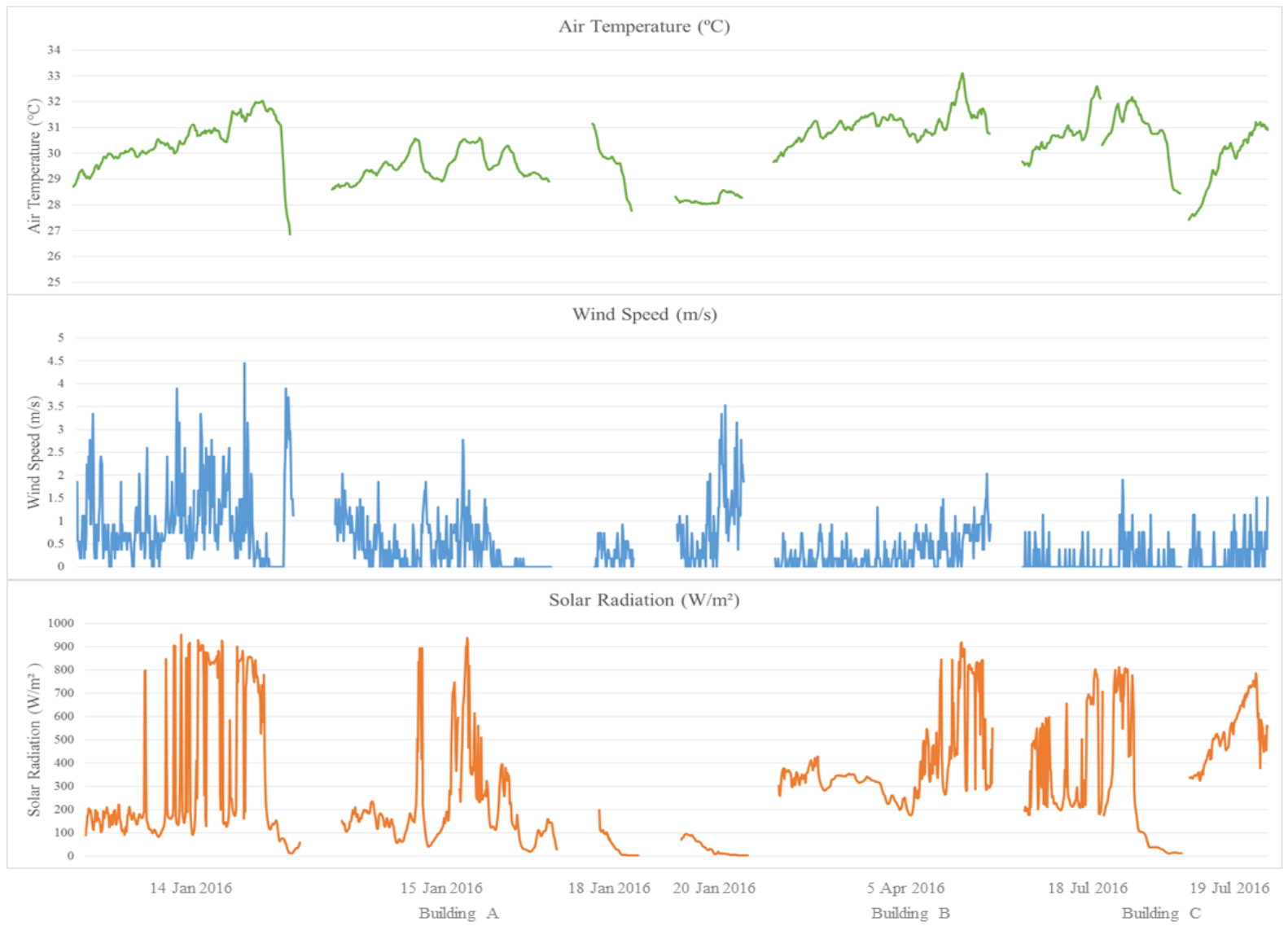

Fig. 4. Outdoor Weather Condition

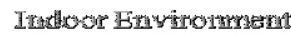

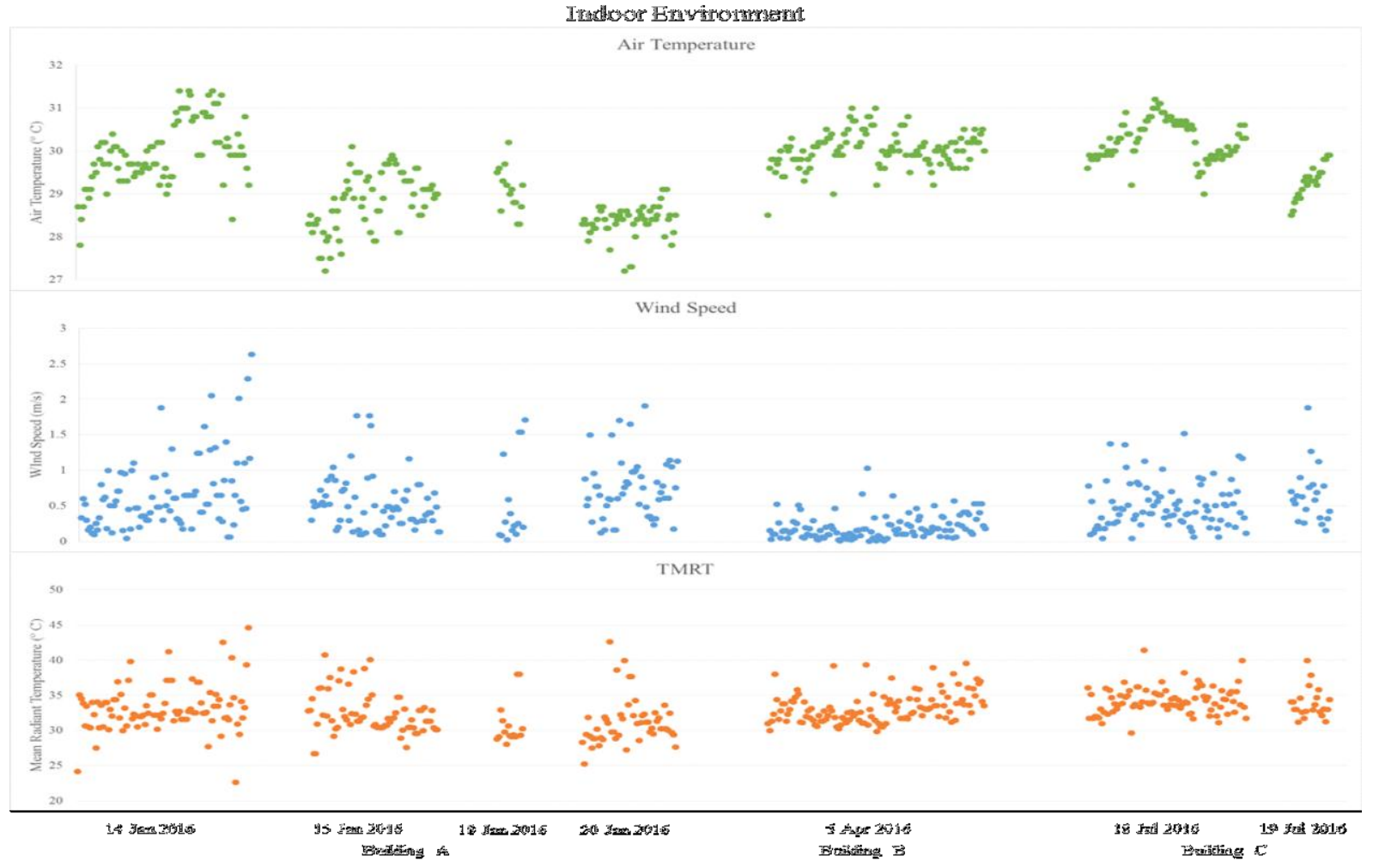

Fig. 5. Respondents' Environment Measurement 
Figure 5 shows the measured data and the summary of air temperature $\left({ }^{\circ} \mathrm{C}\right)$, mean radiant temperature $\left({ }^{\circ} \mathrm{C}\right)$ and wind speed $(\mathrm{m} / \mathrm{s})$ of all respondents respectively. Generally, the trend of the measured indoor air temperature follows the trend of the outdoor air temperature. Indoor air temperature increases when outdoor air temperature increases.

The survey at building A was conducted on bright condition that turned into cloudy and rain in the afternoon. TC survey at building B was conducted during bright day. The indoor environment in building $\mathrm{C}$ almost have the same pattern with building $\mathrm{B}$. The indoor wind speed was measured mostly at the range of $0.2-0.7 \mathrm{~m} / \mathrm{s}$, while mean radiant temperature was at the range of $31-34^{\circ} \mathrm{C}$.

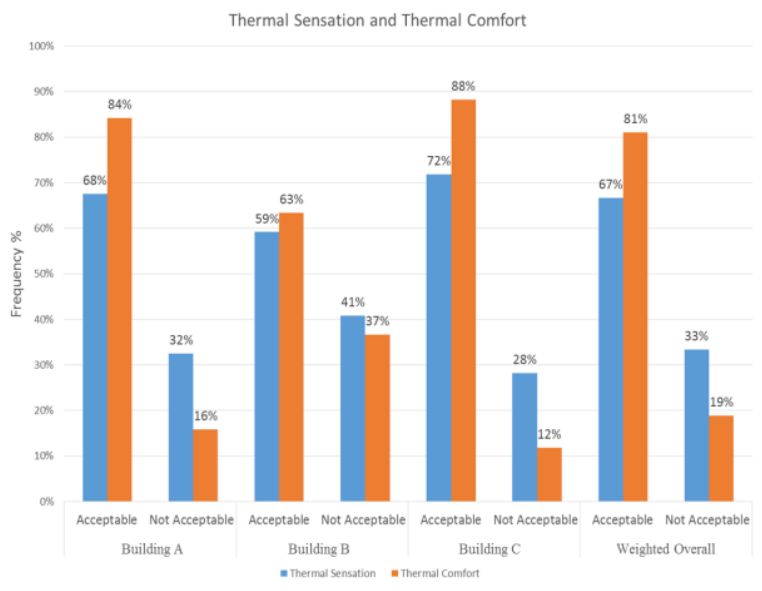

Fig. 6. Thermal Acceptability Graph

\section{Thermal Comfort Model Development and Validation}

The thermal comfort survey data is divided into two groups, i.e. one set for model development (371 data) and one set for model validation (93 data). Weighted estimation was made to determine the number of respondents selected from each site and each session for validation purpose.

The computation of the statistical analysis used SPSS ${ }^{\circledR}$ Version 23 software. Multiple Regression Analysis is the most common statistical tools used by many TC researchers to develop TC indices (Webb, 1959; Sharma \& Ali, 1986), it was employed to find the best correlation between the Predicted Mean Vote (PMV) as dependent variable, and the set of environmental variables as independent variables. Clothing was included because in during the survey, the respondents wore different clothes.

Using the data set for model development, correlation between the dependent variable PMV and independent variables are depicted in Table 2.

Correlations and linear regressions were conducted. Through the Pearson Correlation, DBT, WIND, and RH are found to be significant as highlighted in Table 2. A trend analysis was done to explain the variables by examining the independent variables' regression coefficient values (B) and their correlations with the dependent variable using Pearson correlation (r). Correlation significance level was also examined based on $\mathrm{p}<0.05$.

Table 2. Inter-Correlation between Independent Variables and PMV

\begin{tabular}{llrrrrrrr}
\hline & PMV & DBT & RH & WIND & TMRT & CLO & MET \\
\hline PMV & Pearson Correlation & 1 & .246 & -.253 & -.256 & .002 & -.018 & -.044 \\
& Sig. at 0.05 level (2-tailed) & & .000 & .000 & .000 & .973 & .726 & .397 \\
DBT & Pearson Correlation & .246 & 1 & -.412 & -.158 & .027 & -.149 & -.097 \\
& Sig. at 0.05 level (2-tailed) & .000 & & .000 & .002 & .598 & .004 & .061 \\
RH & Pearson Correlation & -.253 & -.412 & 1 & .223 & -.134 & -.088 & .040 \\
& Sig. at 0.05 level (2-tailed) & .000 & .000 & & .000 & .010 & .090 & .448 \\
WINDD & Pearson Correlation & -.256 & -.158 & .223 & 1 & .387 & -.061 & .079 \\
& Sig. at 0.05 level (2-tailed) & .000 & .002 & .000 & & .000 & .240 & .130 \\
TMRT Pearson Correlation & .002 & .027 & -.134 & .387 & 1 & -.024 & .067 \\
\multirow{2}{*}{ CLO } & Sig. at 0.05 level (2-tailed) & .973 & .598 & .010 & .000 & & .644 & .198 \\
& Pearson Correlation & -.018 & -.149 & -.088 & -.061 & -.024 & 1 & -.048 \\
& Sig. at 0.05 level (2-tailed) & .726 & .004 & .090 & .240 & .644 & .357 \\
MET & Pearson Correlation & -.044 & -.097 & .040 & .079 & .067 & -.048 & 1 \\
& Sig. at 0.05 level (2-tailed) & .397 & .061 & .448 & .130 & .198 & .357 & \\
\hline
\end{tabular}

Table 3. Combinations of Environmental Variables

\begin{tabular}{llrrrrrrr}
\hline & \multicolumn{7}{c}{ Variables in equation } \\
\hline No & Combinations & DBT & RH & WIND & Constant & $\mathrm{R}^{2}$ & Adjusted R & Residual Mean Square \\
\hline 1 & DBT WIND & 0.343 & - & -0.747 & -9.252 & 0.109 & 0.104 & 1.822 \\
2 & DBT WIND RH & 0.252 & -0.032 & -0.668 & -4.221 & 0.125 & 0.118 & 1.793 \\
\hline
\end{tabular}


In the statistical analysis process, it was found that DBT, RH, and WIND were the significant independent variables. From all combinations in the multiple regression analysis, the combinations that all independent variables combined are significant, as shown in Table 3. Since people are adapted to hot humid condition and in order to standardized PMV models for different building types, Combination 1 is considered for the thermal comfort model.

The equation based on Combination 1 can be written as follows:

PMV $=0.343$ DBT -0.747 WIND -9.252

Figure 7 shows the boxplot of measured PMV and predicted PMV using the data set for model validation. The descriptive of the data is shown in Table 4. Based on median value, the PMV model seems to under predict towards cooler side, but in overall, $80 \%$ of the predicted PMV value is within the interquartile range (central tendency) of the measured PMV.

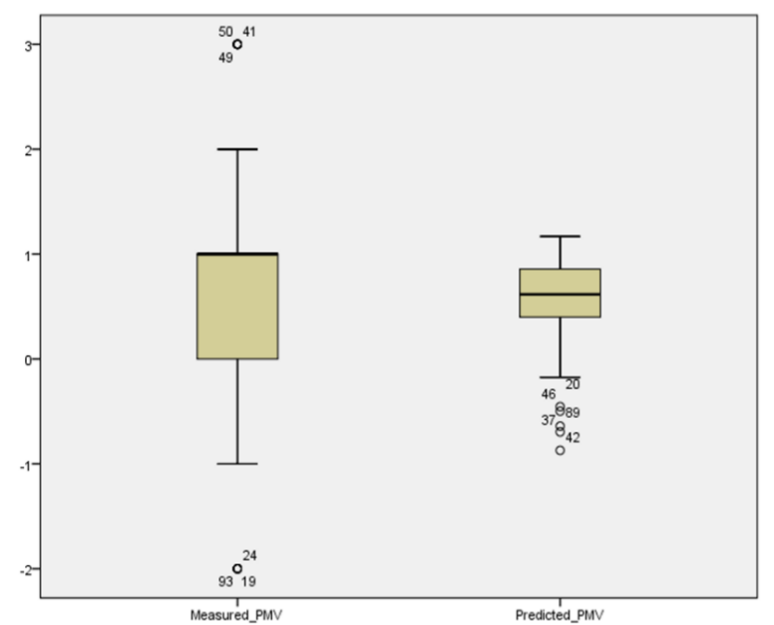

Fig. 7. Comparison of Measured PMV and Predicted PMV for Model Validation

Table 4. Descriptive Data of Boxplot Graph

\begin{tabular}{lrrrr}
\hline & Min. Max. Median & Interquartile Range \\
\hline Measured PMV & -2 & 3 & 1 & $0-1$ \\
Predicted PMV & -0.9 & 1.4 & 0.63 & $0.3-0.9$ \\
\hline
\end{tabular}

\section{Boundary Condition}

The PMV equations have two components, i.e. DBT and WIND. For WIND, indoor wind speed with or without fans shall be derived from CFD simulation. For DBT, Changi meteorological weather station air temperature (dry bulb temperature) of 32 years was analyzed.
Since the atriums are inside commercial/public buildings that generally operate at around 9am to 6pm daily, the analysis was also conducted for this period. There were two approaches being looked into. The first approach was by daily averaging the DBT at 9am to $6 \mathrm{pm}$, and the second approach was by grouping the hourly DBT from the weather station data directly into the DBT bins without daily averaging. From this analysis, the most frequently occurred DBT from both approaches is $30^{\circ} \mathrm{C}$.

Most of the atriums used for the thermal comfort survey did not use skylight and hence, the effect of solar radiation on ambient air temperature might not be shown in the analysis. The survey also only managed to get thermal perception from passerby rather than from participants of event held in atriums.

Therefore, DBT as boundary condition for NV atriums is raised to $31^{\circ} \mathrm{C}$ from $30^{\circ} \mathrm{C}$. The reasons are:

1. To factor in the effect of solar radiation on ambient air temperature because atriums may use skylight; and

2. To factor in the heat load from people gathering during event held in the atrium.

\section{Sensitivity Analysis}

Table 5 shows the various wind speed required based on air temperature of $31^{\circ} \mathrm{C}$ to achieve various PMV values, and the various air temperature required based on wind speed of $0.6 \mathrm{~m} / \mathrm{s}$ to achieve various PMV values respectively. The air temperature of $31^{\circ} \mathrm{C}$ was determined as the boundary condition.

Table 5. Various Wind Speed Required to Achieved Various PMV Values

\begin{tabular}{ccc}
\hline DBT $\left({ }^{\circ} \mathrm{C}\right)$ & WIND $(\mathrm{m} / \mathrm{s})$ & PMV \\
\hline 31 & 0.51 & 1.0 \\
31 & 0.78 & 0.8 \\
31 & 0.91 & 0.7 \\
31 & 1.18 & 0.5 \\
\hline
\end{tabular}

\section{CONCLUSION}

PMV model for naturally-ventilated atrium is;

$\mathrm{PMV}=0.343$ DBT -0.747 WIND -9.252

Which DBT is indoor air temperature $\left({ }^{\circ} \mathrm{C}\right)$ with baseline at $31^{\circ} \mathrm{C}$ and WIND is indoor wind speed $(\mathrm{m} / \mathrm{s})$.

By using DBT $31^{\circ} \mathrm{C}$, PMV 1 is the highest acceptable value with wind speed required is $0.51 \mathrm{~m} / \mathrm{s}$ and PMV 0.8 is recommended to achieve the best thermal comfort with wind speed required is $0.78 \mathrm{~m} / \mathrm{s}$ which is within the most frequently measured indoor wind speed during the survey $(0.2-0.7 \mathrm{~m} / \mathrm{s})$. For PMV 
below the value of 0.8 , the high wind speed might be too drafty (See Table 5), and it is not recommended.

\section{ACKNOWLEDGMENT}

This paper is part of the research project "Development of Computation Fluid Dynamic (CFD) Simulation Methodology and Evaluation parameters, Thermal Comfort Model \& Simulation Methodology for Wind Driven Rain in Natural Ventilated Building for Non-Residential Buildings (NRB) BCA Green Mark Criteria" funded by Building and Construction Authority (BCA) Research \& Innovation Fund grant number 1.51.602.22153.00, and managed by Institute of High Performance Computing (IHPC). The authors would like to thank National Library Board Singapore for the technical support during one of the surveys.

\section{REFERENCES}

Building and Construction Authority. (2013). BCA Green Mark for New Non-Residential Buildings Version NRB/4.1.

De Dear, R.J. et al. (2013). Review Article: Progress in Thermal Comfort Research over the Last Twenty Years. Indoor Air, 23, pp.442-461. Jhon Wiley \& Sons Ltd.
Yeang, K. (1987). Tropical Urban Regionalism: Building in South-east Asian City. Concept Media. Singapore.

Moosavi, L. et al. (2014). Renewable and sustainable energy reviews, pp. 654-670.

Brager, G.S. \& De Dear, R.J. (1998). Thermal Adaptation in the Built Environment: A Literature Review. Energy and Buildings, 27, pp. 83-96. Elsevier.

Kalz, E.D. \& Pfafferott, J. (2014). Thermal Comfort and Energy-Efficient Cooling of Nonresidential Buildings. SpringerBriefs in Applied Sciences and Technology.

Chrenko, F.A. \& Bedford. (1974). Bedford's Basic Principles of Ventilation and Heating. HK Lewis and co. London.

McIntyre, D.A. (1980). Indoor Climate. Applied Science Publishers. London.

Webb, C.G. (1959). An Analysis of Some Observations of Thermal Comfort in an Equatorial Climate. British Journal of Industrial Medicine, 16, pp. 297-310.

Sharma, M.R. \& Ali, S. (1986). Tropical Summer Index - A Study of Thermal Comfort of Indian Subjects. Building and Environment, 21, pp. 1124. Pergamon. 